\title{
Archéopages
}

Archéopages

Archéologie et société

$36 \mid 01 / 2013$

Exotismes

\section{Le vase tonnelet à décor de singe musicien}

\section{Maxime Mortreau}

\section{OpenEdition}

Journals

Édition électronique

URL : https://journals.openedition.org/archeopages/208

DOI : 10.4000/archeopages.208

ISSN : 2269-9872

\section{Éditeur}

INRAP - Institut national de recherches archéologiques préventives

\section{Édition imprimée}

Date de publication : 1 novembre 2013

Pagination : 18-19

ISSN : 1622-8545

\section{Référence électronique}

Maxime Mortreau, "Le vase tonnelet à décor de singe musicien », Archéopages [En ligne], 36।

01/2013, mis en ligne le 01 janvier 2015, consulté le 21 janvier 2022. URL : http://

journals.openedition.org/archeopages/208; DOI : https://doi.org/10.4000/archeopages.208 

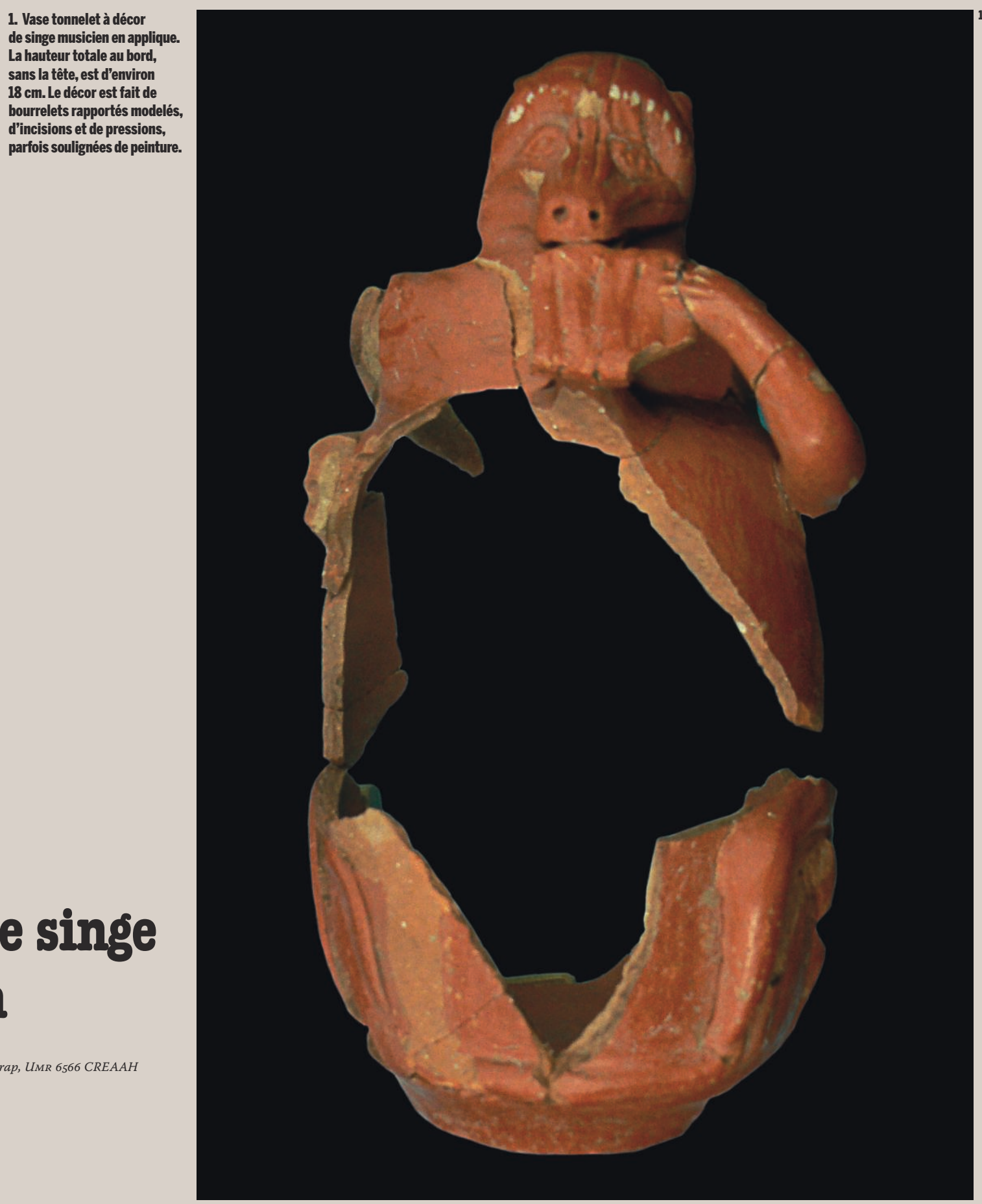

\title{
Le vase tonnelet à décor de singe musicien
}

\author{
Maxime Mortreau ${ }^{\text {Inrap, UMR } 6566 \text { CREAAH }}$
}

La fouille des niveaux de destruction du mithraeum d'Angers a livré 24 fragments d'un vase à décor d'applique figurant un singe musicien, tenant dans ses deux mains une flûte de Pan, ou syrinx, qu'il porte à sa bouche [ill. 1]. La forme générale du vase affecte celle d'un tonnelet: un col droit surmonte une panse ovoïde resserrée à la liaison avec un fond plat offrant un diamètre maximum de $7 \mathrm{~cm}$. En partie opposé à la tête, le rebord montre une déformation matérialisant la capuche du célèbre petit manteau gaulois, le cucullus. En position abaissée sur les épaules, elle prend la forme d'un bec verseur. Sur le pourtour du récipient, six arcades formées de bandes pourraient suggérer le fauteuil dans lequel le singe est assis. L'état de fragmentation du vase ne permet pas de déterminer le sexe de l'animal. Quant à la difficulté de déterminer son espèce (babouin ou macaque), elle est peut-être due au fait qu'il s'agit d'une copie que l'on peut qualifier de maladroite si on la compare à d'autres, plus soignées, comme celle découverte rue de l'ícu à Reims (Rollet, Louis, 2005). Le singe ne serait-il utilisé ici qu'en simple élément décoratif?

Ce type de vase, par son style plastique et par sa technique céramique, ne semble guère avoir fait son apparition avant le $\mathrm{III}^{\mathrm{e}}$ siècle. Sa pâte céramique à engobe rouge lustré a l'aspect des productions 
poitevines du type céramique à l'éponge : argile fine de teinte ocre à cœur beige clair comprenant des éclats de silex blanc, des nodules d'oxyde de fer et des grains de feldspath.

Plusieurs éléments permettent d'émettre l'hypothèse que ce vase zoomorphe a été conçu pour un usage cultuel. Tout d'abord sa rareté : par son aspect exceptionnel, le vase zoomorphe d'Angers semble le fruit d'une commande spécifique passée dans un atelier du centre-ouest de la Gaule. Sa position stratigraphique et son contexte archéologique permettent d'écarter toute récupération opportuniste. Seuls deux autres vases à décor de singe sont connus et ont été retrouvés dans les sanctuaires privés du $\mathrm{nr}^{\mathrm{e}}$ siècle de Reims et dans ceux de Cybèle et Attis datés du rv $\mathbf{r}^{e}$ siècle à Arras (Belot, Blondiaux, 1990). Dans le premier cas, il s'agit d'un vase à décor de singe ithyphallique, issu des ateliers de sigillée de la Gaule centrale, dont la présence à Reims se justifie par le biais d'une commande particulière. Dans le second cas, le vase en terre rouge imite par sa forme la vaisselle de verre. Les spécialistes du verre des siècles derniers y voyaient une figuration caricaturale du dieu Hermès (Aus'm Weerth, 1866 ; Morin, 1913 ; Hellenkemper, 1988), dont le singe était l'animal sacré, ou bien du dieu Pan, la présence de la flûte étant pour beaucoup dans cette identification (Kisa, 1908). Si une origine égyptienne de l'iconographie simiesque n'est pas à exclure, elle semble toutefois se répandre assez vite en Gaule après la conquête romaine : on la retrouve en effet sous forme de figurines dans le répertoire des terres blanches, glaçurées ou non, produites dans les grands ateliers de la vallée de l'Allier du $\mathrm{r}^{\mathrm{er}}$ au $\mathrm{Ir}^{\mathrm{e}}$ siècle (Tudot, 1860 ; Blanchet, 1901 ; RouvierJeanlin, 1972 ; Corrocher 1983). Il est à noter que certains de ces primates sont vêtus du cucullus.

Quel peut être le rapport entre le vase à décor de singe musicien et le culte mithriaque ? Aucun élément ne vient étayer un quelconque rapport entre Mithra et le singe dans la bibliographie consultée. Si on examine les différents objets remarquables mis au jour sur le site du mithraeum, on note cependant que les artefacts ayant trait à d'autres dieux sont également présents : fragment d'une figurine en terre sigillée représentant Mercure/Hermès [ill. 2] - association connue dans les Alpes ; applique décorative en bronze figurant Bacchus ou un faune. Une réponse consiste peut-être à considérer que la longue durée de l'existence du culte de Mithra à Angers (entre 170 et 405) ne peut s'expliquer que par la présence d'un nombre suffisant d'adeptes recrutés chez les militaires et les fonctionnaires impériaux. Ceux-ci avaient sans doute des religions diverses, car il est probable que le culte mithriaque n'était pas le seul culte d'origine orientale à Angers. Le vase serait-il alors un emprunt à un autre culte ?

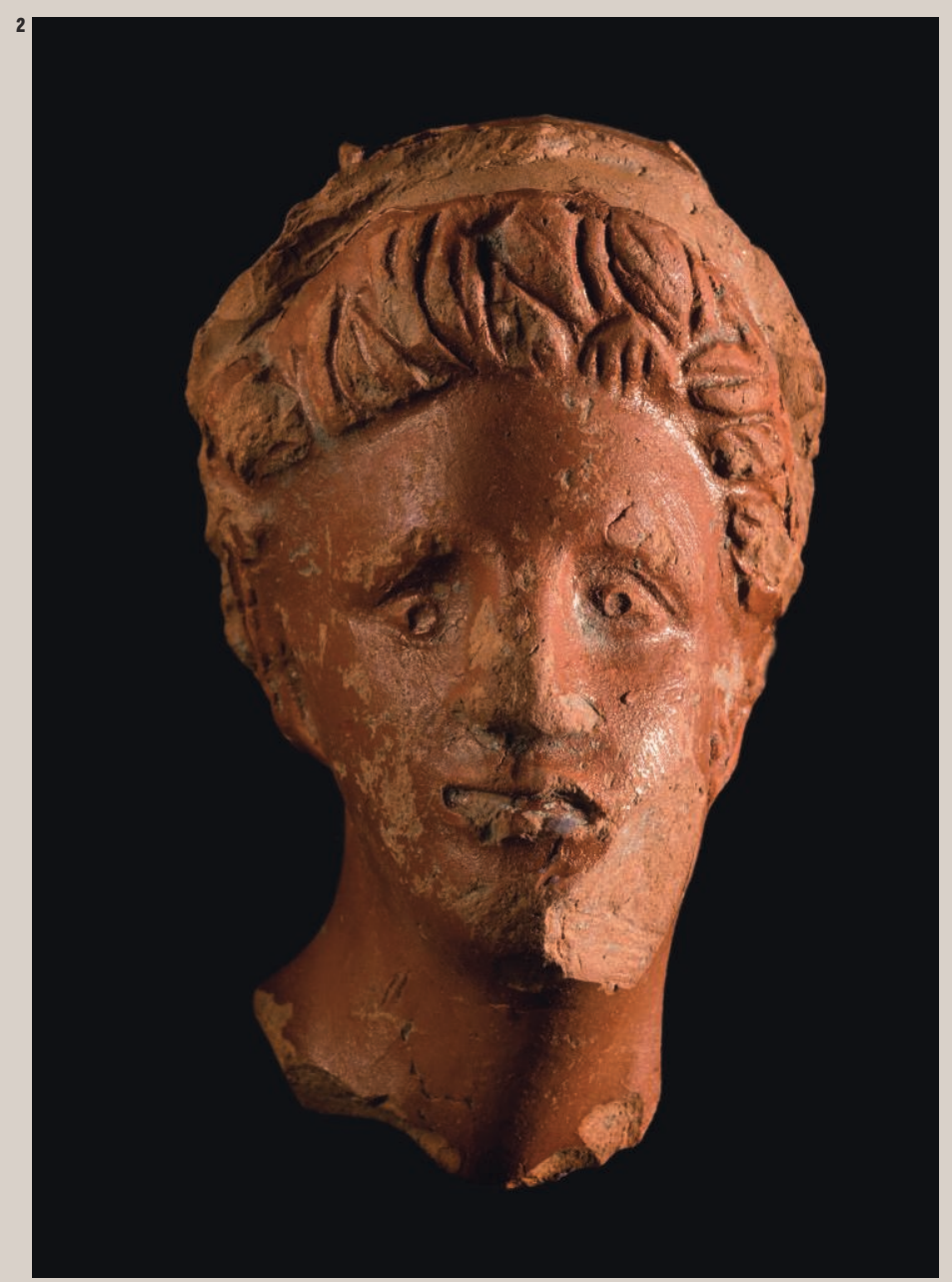

2. Fragment de statuette de Mercure. Terre sigillée, atelier de Gaule centrale (160-230).

Références bibliographiques

AUS'M WEERTH E., 1866 : «Zwei römische Glasgefässe aus der Sammlung des Herrn Carl Disch zu Köln », Bonner Jahrbücher, 41, p. 142-145, pl. 3-4.

Belot É., Blondiaux J., 1990 : Les cultes à Arras au Bas-Empire, Catalogue d'exposition, Musée des beaux-arts d'Arras, 1990, Arras, Musée des beaux-arts.

BLANCHET A., 1901 : «Étude sur les figurines de terre cuite de la Gaule romaine», Mémoires de la Société nationale des antiquaires de France, t. LX, p. 189-272.

CORrocher J., 1983 : « La céramique à glaçure plombifère de Vichy (Allier) », Revue archéologique du centre de la France, vol. XXII, 1, p. 15-40.

Hellenkemper H., 1988: «Fiaschetta a forma di scimmia », in Harden D. B. et al., Vetri dei Cesari, Milan, Olivetti, p. 173

KISA A., 1908 : Das Glas im Altertume, 3 vol., Leipzig.

LECLANT J., 1976 : «L'Égypte, terre d'Afrique dans le monde gréco-romain ", in VERCOUTTER J., LECLANT J., SNOWden F. M., Desanges J., L'image du Noir dans l'art occidental, vol. 1, Des pharaons à la chute de l'Empire romain, Fribourg, Office du Livre, p. 269-285.

MORIN J., 1913 : La verrerie en Gaule sous l'Empire romain Laurens, Paris, $306 \mathrm{p}$

Rollet P., Louis A., 2005 : Reims, (Marne) 30/32-34, rue de l'Écu, Rapport final d'opération, SRA ChampagneArdenne/INRAP, Reims, 2005, 122 p.

ROUVIER-JEANLIN M., 1972 : Les figurines gallo-romaines en terre cuite au musée des Antiquités nationales, Paris, CNRS (coll. Suppl. à Gallia, 24), 428 p.

Tudot E., 1860: « Les statuettes en terre cuite du centre de la Gaule», Revue archéologique Sites, hors-série n 23. 